\title{
A surface and catalytic investigation of ceria by laser desorption ionization mass spectrometry
}

\author{
I. V. Zagaynov ${ }^{1}$, A. K. Buryak ${ }^{2}$ \\ ${ }^{1}$ A. A. Baikov Institute of Metallurgy and Materials Science, Leninskii pr. 49, Moscow, Russia \\ ${ }^{2}$ A. N. Frumkin Institute of Physical Chemistry and Electrochemistry, Leninskii pr. 31, Moscow, Russia \\ ${ }^{1}$ igorscience@gmail.com
}

PACS 61.46.-w, 68.43.-h

DOI 10.17586/2220-8054-2017-8-2-290-295

$\mathrm{Gd}_{0.1} \mathrm{Ti}_{0.1} \mathrm{Zr}_{0.1} \mathrm{Ce}_{0.7} \mathrm{O}_{2}$ solid solution with crystallite size of $10 \mathrm{~nm}$, specific surface area of $85 \mathrm{~m}^{2} / \mathrm{g}$ and pore size of $2-6 \mathrm{~nm}$ has been prepared by a simple co-precipitation method with sonication and characterized by several methods. Among the characterization methods was laser desorption ionization-time of flight mass spectrometry (LDI-TOF) which was used to characterize the surface of the catalyst (fresh and used in $\mathrm{CO}$ oxidation) and thereby determine the catalytic sites (active sites of oxidation).

Keywords: ceria, solid solution, CO oxidation, LDI-TOF.

Received: 17 November 2016

Revised: 14 December 2016

\section{Introduction}

Nanocrystalline ceria based materials are playing an important role in environmental and energy related applications, especially in areas such as catalysis. Doped ceria materials are considered as more promising solid solutions for the use in these applications. The choice of a suitable dopant however, still remains a major challenge to the scientific community in terms of oxygen storage capacity, thermal stability, and economical considerations. Substitution of $\mathrm{Ce}^{4+}$ by other dopants in ceria leads to solid solutions which are found to increase both the oxygen storage capacity (OSC) and ionic conductivity as well as directly impact the catalytic activities. The activity is also dependent on other parameters such as the size, morphology and type of dopants. The presence of oxygen vacancies, especially for occurring interface reactions, in ceria-based materials is one of the key factors in oxidation reactions. Therefore, the investigation and characterization of the surface (interface) is an important goal [1-5]. To explore this key factor, the structural and morphological properties of fresh and spent catalysts were examined using XPS, EXAFS, XANES and other techniques. At the same time, mass spectrometry is widely used to measure molecular mass by ionizing the sample and report information [6,7], but did not in catalyst surface characterization. To obtain information on the nanoparticle's surface, they have to not undergo decomposition during ionization and detection. Clusters or nanodomains [8] of reduced ceria in the form of nonstoichiometric phase over the surface, likely originated from the reduction of ceria at the ceria interface, are giving direct evidence of the important role of the redox of ceria based materials. This means that the use of "soft ionization" methods to study such labile structures cannot be overestimated, it remains the only available method to accurately determine the mass, the number of atoms and molecules inside the nanodomain (cluster). Therefore, laser desorption ionization-time of flight mass spectrometry (LDI-TOF) method was used in this work to characterize the surface and establish active sites of oxidation $[9,10]$. This method can be used to characterize the surface of nanoparticles, bulk materials, ceramics and other relevant materials.

\section{Material and methods}

\subsection{Synthesis}

$\mathrm{Ce}\left(\mathrm{NO}_{3}\right)_{3} \cdot 6 \mathrm{H}_{2} \mathrm{O}, \mathrm{ZrO}\left(\mathrm{NO}_{3}\right)_{2} \cdot 6 \mathrm{H}_{2} \mathrm{O}, \mathrm{Gd}\left(\mathrm{NO}_{3}\right)_{3} \cdot 6 \mathrm{H}_{2} \mathrm{O}, \mathrm{TiCl}_{4}$ (Acros Organics) were used as metal precursors. Appropriate amounts of salts were dissolved in $500 \mathrm{~mL}$ distilled water containing of nitric acid $(\mathrm{pH}=2)$ to give total concentrations of metals of $0.04 \mathrm{M}$. Then, the co-precipitation of hydroxides was carried out by addition of aqueous ammonia up to $\mathrm{pH} 10$ at $30{ }^{\circ} \mathrm{C}$ under stirring. Ultrasonic processing $(10 \mathrm{~min}, 35 \mathrm{kHz}, 150 \mathrm{~W}$, Sapphire $\mathrm{UZV-4.0)}$ was used during dissolution of salts in distilled water and after precipitation. The resulting precipitates were filtered, washed with distilled water-ethanol solution $\left(\mathrm{H}_{2} \mathrm{O} / \mathrm{C}_{2} \mathrm{H}_{5} \mathrm{OH}=9\right.$ vol. $)$, dried at $150{ }^{\circ} \mathrm{C}$ for $12 \mathrm{~h}$, and calcined in static air by heating at a rate of $4{ }^{\circ} \mathrm{C} / \mathrm{min}$ from room temperature to $500{ }^{\circ} \mathrm{C}$ and kept at $500{ }^{\circ} \mathrm{C}$ for $1 \mathrm{~h}$ in a muffle furnace. 


\subsection{Characterization}

Powder XRD data were collected at room temperature (Rigaku MiniFlex 600) with $\mathrm{CuK} \alpha$ radiation. Particle size $\left({ }^{\mathrm{d}} \mathrm{XRD}\right)$ was calculated by Scherrer equation taking into account the instrumental broadening using germanium as reference; ${ }^{\mathrm{d}} \mathrm{XRD}$ was calculated from (111), (220), (311) peaks. Quantitative phase analysis was calculated by the Rietveld method.

Specific surface area $\left({ }^{\mathrm{S}} \mathrm{BET}\right)$ of the powders was measured by a conventional nitrogen adsorption method at $77 \mathrm{~K}$ (TriStar 3000 Micromeritics). Pore-size distributions were calculated from desorption isotherm, using BJH method. Samples were degassed at $120^{\circ} \mathrm{C}$ for $5 \mathrm{~h}$ prior to measurement.

TEM analyses were conducted on an Omega Leo-912AB transmission electron microscope with accelerating voltage of $100 \mathrm{kV}$.

The XPS spectra were measured on an Axis Ultra DLD spectrometer (Kratos Analytical) using a monochromatic $\mathrm{AlK} \alpha$ source $(1486.6 \mathrm{eV}, 150 \mathrm{~W})$. The spectrometer was operated in fixed analysis energy mode, with a pass energy of $20 \mathrm{eV}$ for high resolution spectra and $160 \mathrm{eV}$ for survey spectra. The photoelectron spectra were recorded with $0.1 \mathrm{eV}$ increments. The energy scale of spectrometer was calibrated according to the standard procedure with respect to $\mathrm{Au} 4 \mathrm{f}_{7 / 2}, \mathrm{Ag} 3 \mathrm{~d}_{5 / 2}$, and $\mathrm{Cu} 2 \mathrm{p}_{3 / 2}$ photoelectron peaks of pure metals at 83.96, 368.21 and $932.62 \mathrm{eV}$, respectively. The surface charging effect in the spectra was compensated against the $\mathrm{C}-\mathrm{H}$ states in the $\mathrm{C} 1 \mathrm{~s}$ spectra with the energy assumed to be $285.0 \mathrm{eV}$. The measurements were carried out at a pressure of $10^{-7} \mathrm{~Pa}$ at room temperature. Quantitative surface chemical analyses were calculated from the high-resolution core-level spectra, following the removal of a non-linear Shirley background.

Mass spectrometric analysis was performed using a MALDI-TOF mass spectrometer (Bruker UltraFlex 2) equipped with a $337 \mathrm{~nm} 110 \mu \mathrm{J}$ nitrogen laser. All measurements were performed in the linear mode by detecting positive and negative ions. Mass spectra were recorded with a laser power of 80-95\% of maximum. "Shots" were carried out in different parts of the samples. At the target, a surface double-sided tape was placed on stainless steel, on which the samples were applied and then dried at room temperature. On the basis of the molecular-mass isotope distribution patterns, formulas of proposed compounds corresponding to the $\mathrm{m} / \mathrm{z}$ ratios are proposed.

The catalytic activity of the synthesized samples in the oxidation of CO was determined by the flow method at atmospheric pressure. The process was conducted in a U-shaped quartz reactor at a gas hourly space velocity of $1800 \mathrm{~h}^{-1}$ within a temperature range of $20-500{ }^{\circ} \mathrm{C}$. The temperature was measured with a thermocouple placed in the center of the catalytic bed. The model gas mixture had the following composition, vol. \%: $\mathrm{CO}-4.2 ; \mathrm{O}_{2}-$ 9.6; $\mathrm{N}_{2}$ - balance. The concentrations of gases were measured on a Konik-Tech HRGC 5000B gas chromatograph.

\section{Results and discussion}

XRD patterns (Fig. 1a) of fresh and used catalysts are perfectly indexed as the pure cubic phase, indicating the formation of solid solutions by the incorporation of respective dopant ions into the ceria lattice and stability of this system during catalysis. According to TEM (Fig. 1b), the images reveal that the particle size is about $10 \mathrm{~nm}$ and nearly spherical in shape with an agglomerated structure. All samples have IV type adsorption curves with a hysteresis loop of $\mathrm{H} 2$, indicating the presence of mesopores in the systems [11]. The pore size distribution of samples (polymodal distribution of pores, 2-6 nm) is presented in Fig. 1c. Table 1 traces the evolution of the microstructure of the catalysts before and after catalytic test. It is clearly demonstrated that no phase and morphological changes were observed and the catalyst was stable.

TABLE 1. Main characteristics of ceria-based catalysts

\begin{tabular}{|c|c|c|c|c|c|c|}
\hline No & Sample & $\begin{array}{c}{ }^{\mathrm{d}} \mathrm{XRD}, \\
\mathrm{nm}\end{array}$ & $\begin{array}{c}\mathrm{d}^{\mathrm{T}} \mathrm{TEM}, \\
\mathrm{nm}\end{array}$ & $\begin{array}{c}{ }^{\mathrm{S}} \mathrm{BET}, \\
\mathrm{m}^{2} \mathrm{~g}^{-1}\end{array}$ & $\begin{array}{c}\text { Pore diameter, } \\
\mathrm{nm}\end{array}$ & $\begin{array}{c}\mathrm{T}_{50}\left(\mathrm{~T}_{100}\right) \mathrm{CO} \\
\text { conversion, }{ }^{\circ} \mathrm{C}\end{array}$ \\
\cline { 1 - 6 } fresh & \multirow{2}{*}{$\mathrm{Gd}_{0.1} \mathrm{Ti}_{0.1} \mathrm{Zr}_{0.1} \mathrm{Ce}_{0.7} \mathrm{O}_{2}$} & 9 & $6-12$ & 83 & $2-6$ & $210(263)$ \\
\cline { 1 - 6 } used & & 10 & $7-13$ & 82 & $2-6$ & - \\
\hline
\end{tabular}

Ce $3 \mathrm{~d}$ photoelectron peaks displayed a complex nature of spectrum originated from the existence of multiple oxidation states and overlapping of $\mathrm{Ce} 4 \mathrm{f}$ levels with $\mathrm{O} 2 \mathrm{p}$ states during the primary photoemission process. According to XPS data [12] Ce, Ti, and $\mathrm{Zr}$ cations have charge +4 , and $\mathrm{Gd}$ has +3 ; also the existence of another phase or cation coordination on the surficial region is possible that can be interpreted in terms of the interaction between dopant and cerium species, i.e. Ce-O-Me bond formation, which induced more number of oxygen defects at the interface by the substitution of $\mathrm{Ce}^{4+}$ with the dopant. XPS spectrum indicated the absence of the Ce $\mathrm{e}^{3+}$ state $^{4}$ in these spectra in contrast to other many works, and significant changes were not observed [12]. 


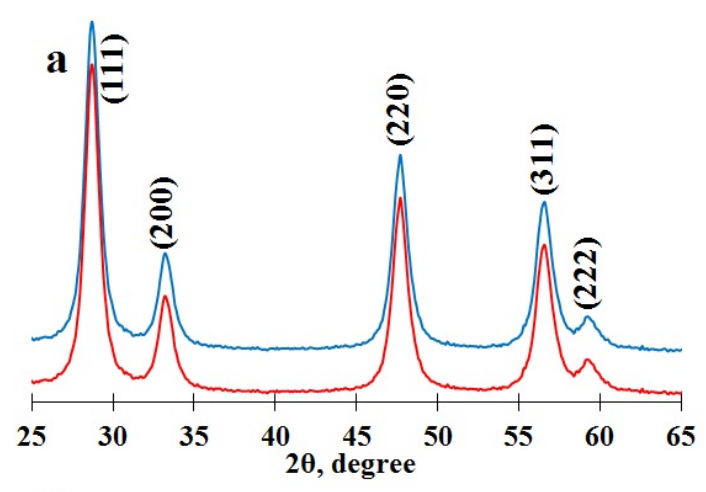

b
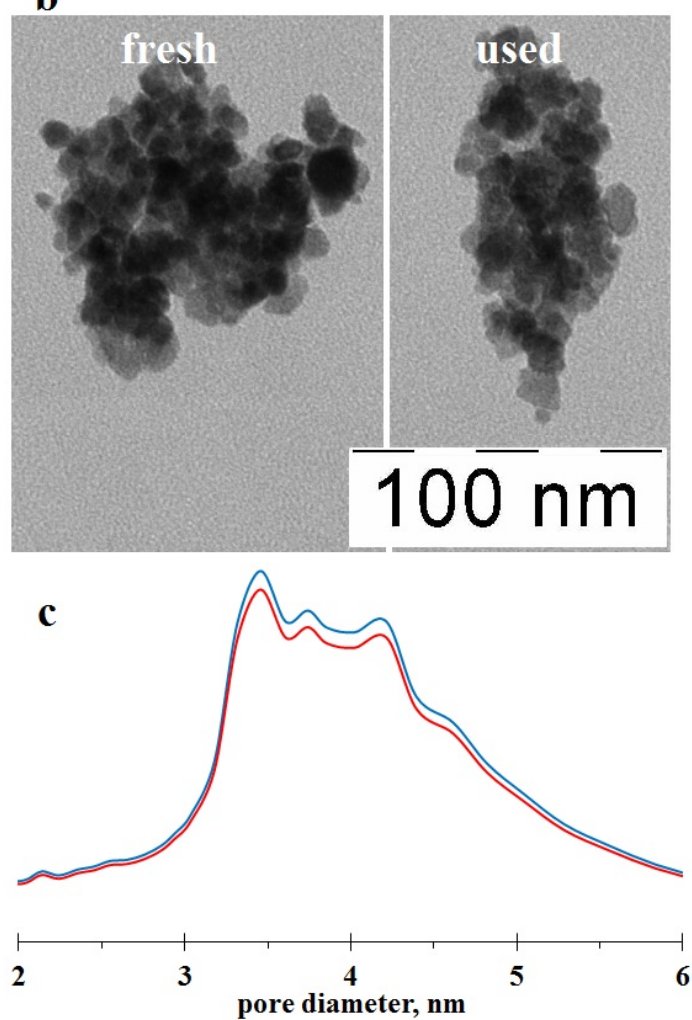

FIG. 1. XRD pattern (a), TEM images (b) and pore size distribution (c) of samples. Blue before catalysis, red - after catalysis

Figure 2 shows LDI-TOF spectra of the samples in the positive and negative ion recording modes. The positive spectra are almost identical, and no evident changes were observed after the catalytic reaction. The main structural cationic fragments in the mass spectra (besides collateral fragments, containing of $\mathrm{Na}, \mathrm{K}, \mathrm{Mg}, \mathrm{Ca} .$. , being only impurities) are presented in Table 2. Fragments of Ce with other dopants are detected. Gd-containing fragments are difficult to identify due to equal $\mathrm{m} / \mathrm{z}$ ratio of $\mathrm{Gd}$ (157) and $\mathrm{CeOH}$ (157) fragments. Also the repeatability of $\mathrm{CeO}\left(\mathrm{CeO}_{2}\right)_{n}$ and $\left(\mathrm{CeO}_{2}\right)_{n}$ fragments (see example in Fig. 2a) are presented. Another situation is in negative spectra (Fig. 2b). The cleaning of surface by $\mathrm{CO}$ was occurred during catalysis. $\mathrm{MeO}_{4}^{-}$fragments are detected, and $\mathrm{Cl}$ - and $(\mathrm{Na}, \mathrm{K}, \mathrm{Mg}, \mathrm{Ca}) \mathrm{CO}_{3}$-containing fragments are not. Fig. 3 shows interesting area of the spectra: $\mathrm{CeO}_{4}^{-}$ fragment, $\mathrm{CO}_{2}$ and $\mathrm{H}_{2} \mathrm{O}$ adsorbed molecules on it were presented in the fresh sample, but after catalytic test $\mathrm{CeO}$ and $\mathrm{CeO}_{2}$ fragments with $\mathrm{CO}_{3}$ functional group $\left(\mathrm{CeOCO}_{3}^{-}\right.$and $\mathrm{CeO}_{2} \mathrm{CO}_{3}^{-}$fragments, accordingly) were. This is in agreement with a redox mechanism where ceria reduction is initiated at the contact-interface area, forming reduced ceria (active catalytic site (special domains [8], like $\left.\mathrm{CeO}_{4}^{-}\right)$and transforms to used site $\left(\mathrm{CeOCO}_{3}^{-}\right.$and $\mathrm{CeO}_{2} \mathrm{CO}_{3}^{-}$), which is then oxidized by gas-phase oxygen and transforms again to $\mathrm{CeO}_{4}^{-}$. So, it can be assumed that the vicinity of the oxidized sites, promoting the adsorption of $\mathrm{CO}$, and reduced sites, promoting the dissociative adsorption of $\mathrm{O}_{2}$, can accelerate the reaction, provided that the reaction limiting step is the reaction of adsorbed 
$\mathrm{CO}$ and dissociative adsorbed oxygen, thus results in a Langmuir-Hinshelwood model, or the chemisorption of CO takes place on the surface, while the lattice oxygen in ceria also involves in the reaction, thus resulting in a Mars van-Krevelen model [13]. Therefore, based on previous and presented LDI-TOF spectra data the proposed steps of the reaction can be suggested (Fig. 4). During the $\mathrm{CO}$ oxidation $\mathrm{Ce}^{4+}$ is reduced to $\mathrm{Ce}^{3+}$, accompanied by extraction of oxygen from the lattice, which is consumed to oxidize $\mathrm{CO}$ to $\mathrm{CO}_{2}$. The defect mobility of oxygen on the surface has a large influence on the CO oxidation activity and is determined critically by the structure, size and morphology of catalyst. The nanosize ceria contributes a high surface area to volume ratio, and doping with transition metal oxides could create even more active defect sites and lead to enhanced CO conversion [14].

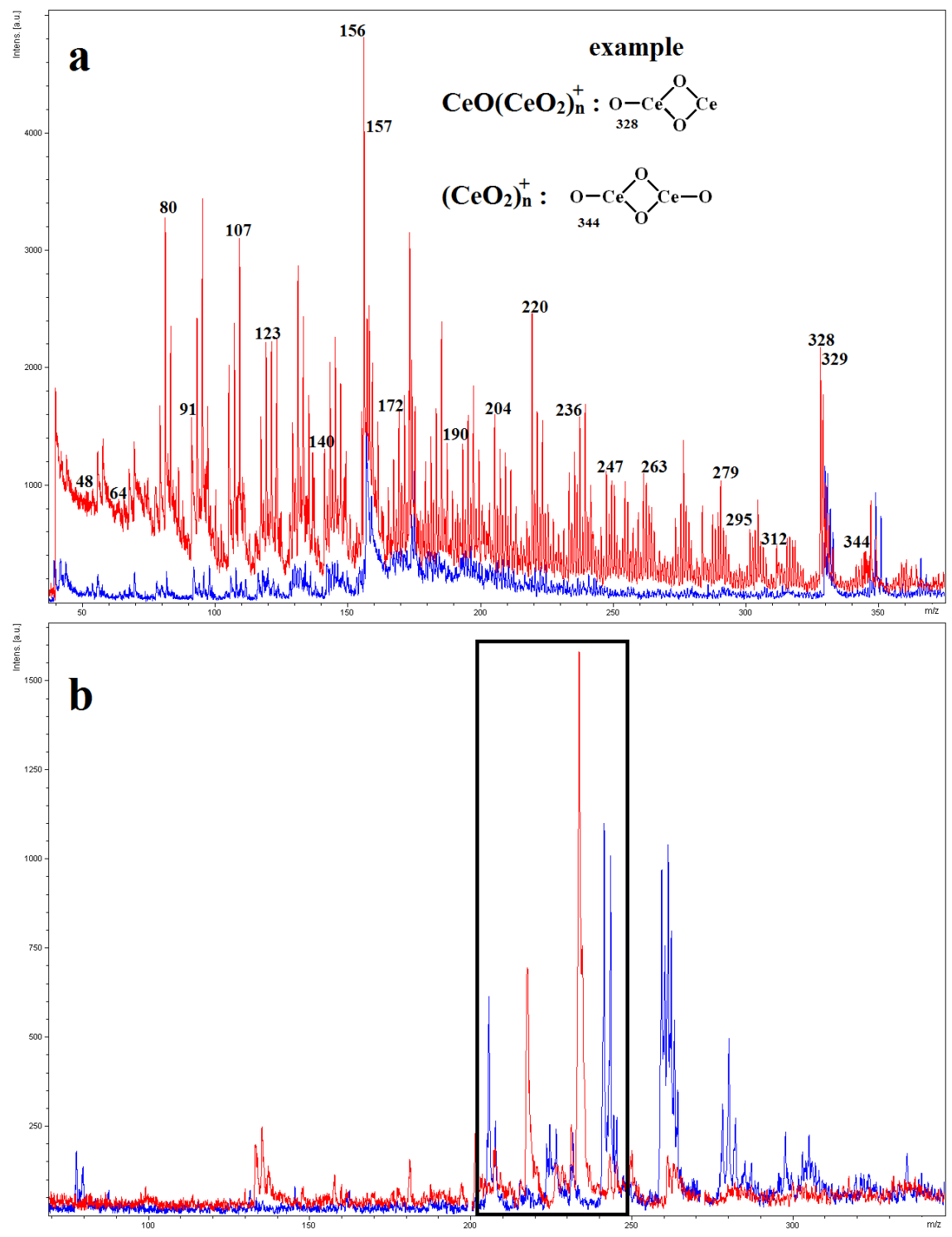

FIG. 2. LDI-TOF spectra of the samples in positive (a) and negative (b) ion recording modes. Blue - before catalysis, red - after catalysis

\section{Conclusions}

Mesoporous materials based on nanosized ceria were synthesized by a sonochemical method and characterized by complex methods. The method of laser desorption ionization-time of flight mass spectrometry (LDI-TOF) was used to characterize the surface of fresh and used after $\mathrm{CO}$ oxidation catalyst and thereby determine the catalytic sites. It was demonstrated that the active sites of oxidation could be proposed by using LDI-TOF data of positive and negative ion fragments and probable steps (possible mechanism) of the reaction could be suggested. Consequently, this work demonstrated that the LDI-TOF mass spectrometry is a promising method for these goals. 
TABLE 2. The main structural cationic fragments in the mass spectra

\begin{tabular}{|c|c|}
\hline ions & $\mathrm{m} / \mathrm{z}, \mathrm{Da}$ \\
\hline $\mathrm{Ti}^{+}$ & 48 \\
\hline $\mathrm{TiO}^{+}$ & 64 \\
\hline $\mathrm{TiO}_{2}{ }^{+}$ & 80 \\
\hline $\mathrm{Zr}^{+}$ & 91 \\
\hline $\mathrm{ZrO}^{+}$ & 107 \\
\hline $\mathrm{ZrO}_{2}{ }^{+}$ & 123 \\
\hline $\mathrm{Ce}^{+}$ & 140 \\
\hline $\mathrm{CeO}^{+}$ & 156 \\
\hline $\mathrm{CeOH}^{+}$ & 157 \\
\hline $\mathrm{Gd}^{+}$ & 157 \\
\hline $\mathrm{CeO}_{2}{ }^{+}$ & 172 \\
\hline $\mathrm{GdO}^{+}$ & 173 \\
\hline $\mathrm{CeO}_{2} \cdot \mathrm{H}_{2} \mathrm{O}^{+}$ & 190 \\
\hline $\mathrm{CeOTi}^{+}$ & 204 \\
\hline $\mathrm{CeOOTi}^{+}$ & 220 \\
\hline $\mathrm{OCeOOTi}^{+}$ & 236 \\
\hline
\end{tabular}

\begin{tabular}{|c|c|}
\hline ions & m/z, Da \\
\hline $\mathrm{CeOZr}^{+}$ & 247 \\
\hline $\mathrm{OCeOOTiO}^{+}$ & 252 \\
\hline $\mathrm{CeOOTi}^{+}$ & 263 \\
\hline $\mathrm{OCeOOZr}^{+}$ & 279 \\
\hline $\mathrm{OCeOOZrO}^{+}$ & 295 \\
\hline $\mathrm{CeOOCe}^{+}$ & 312 \\
\hline $\mathrm{CeOGd}^{+}$ & 313 \\
\hline $\mathrm{CeOOCeO}^{+}$ & 328 \\
\hline $\mathrm{CeOOCeOH}^{+}$ & 329 \\
\hline $\mathrm{CeOOGd}^{+}$ & 329 \\
\hline $\mathrm{OCeOOCeO}^{+}$ & 344 \\
\hline $\mathrm{OCeOOCeO}^{+}$ & 345 \\
\hline $\mathrm{CeOOGdO}^{+}$ & 345 \\
\hline $\mathrm{CeO}_{\left(\mathrm{CeO}_{2}\right)_{n}^{+}}$ \\
\hline$\left(\mathrm{CeO}_{2}\right)_{n}^{+}$ & \\
\hline
\end{tabular}

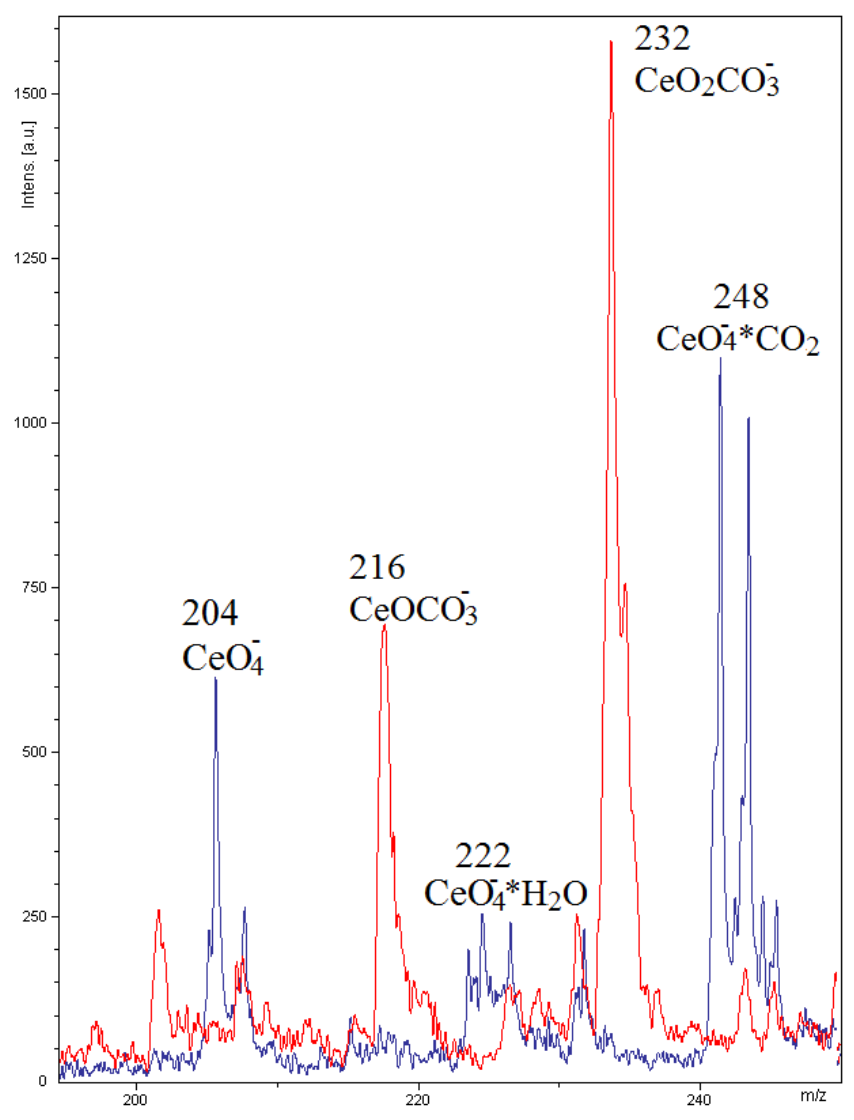

FIG. 3. LDI-TOF spectra of the samples in negative ion recording mode (delineated area in Fig. 1b). Blue - before catalysis, red - after catalysis 


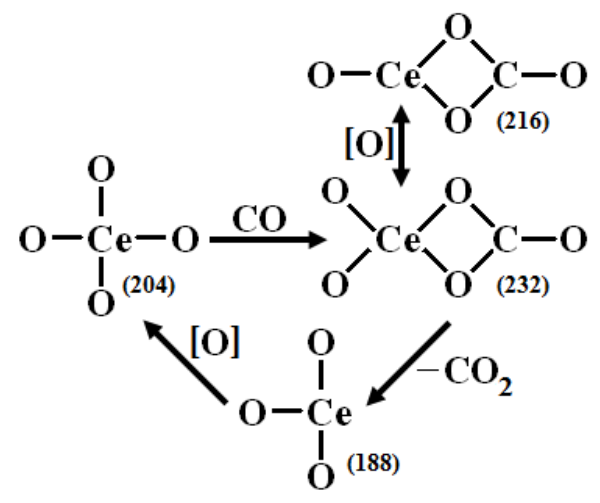

FIG. 4. Representation of possible steps of $\mathrm{CO}$ oxidation reaction in according to LDI-TOF spectra (anionic fragments with charge of -1 )

\section{References}

[1] Trovarelli A. Catalysis by Ceria and Related Materials. World Scientific Publishing Company, Singapore, 2002,528 p.

[2] Trovarelli A., Fornasiero P. Catalysis by Ceria and Related Materials (2nd ed.). World Scientific Publishing Company, Singapore, 2013, 908 p.

[3] Chaudhary S., Sharma P., Kumar R., Mehta S.K. Nanoscale surface designing of cerium oxide nanoparticles for controlling growth, stability, optical and thermal properties. Ceram. Int., 2015, 41, P. 10995-11003.

[4] Venkataswamy P., Jampaiah D., Aniz C.U., Reddy B.M. Investigation of physicochemical properties and catalytic activity of nanostructured $\mathrm{Ce}_{0.7} \mathrm{M}_{0.3} \mathrm{O}_{2-\delta}(\mathrm{M}=\mathrm{Mn}, \mathrm{Fe}, \mathrm{Co})$ solid solutions for $\mathrm{CO}$ oxidation. J. Chem. Sci., 2015, 127, P. 1347-1360.

[5] Vinodkumar T., Durgasri D.N., Maloth S., Reddy B.M. Tuning the structural and catalytic properties of ceria by doping with $\mathrm{Zr}^{4+}$, La ${ }^{3+}$ and $\mathrm{Eu}^{3+}$ cations. J. Chem. Sci., 2015, 127, P. 1145-1153.

[6] Ingram A.J., Boeser C.L., Zare R.N. Going beyond electrospray: mass spectrometric studies of chemical reactions in and on liquids. Chem. Sci., 2016, 7, P. 39-55.

[7] Henderson W., McIndoe J.S. Mass Spectrometry of Inorganic, Coordination and Organometallic Compounds. John Willey \& Sons, London, 2005, $292 \mathrm{p}$

[8] Aneggi E., Divins N.J., et al. The formation of nanodomains of $\mathrm{Ce}_{6} \mathrm{O}_{11}$ in ceria catalyzed soot combustion. J. Catal., 2014, 312, P. 191-194.

[9] Buryak A.K., Serduk T.M. Chromatography-mass spectrometry in aerospace industry. Russ. Chem. Rev., 2013,82 (4), P. $369-392$.

[10] Zagaynov I.V., Buryak A.K. Mesoporous nanoscale ceria: synthesis from cerium (III) acetylacetonate and mechanism. J. Sol-Gel Sci. Technol., 2015, 74, P. 103-108.

[11] Zagaynov I.V. Sonochemical synthesis of mesoporous $\mathrm{Gd}_{x} \mathrm{Zr}_{y} \mathrm{Ti}_{z} \mathrm{Ce}_{1-x-y-z} \mathrm{O}_{2}$ solid solution. Ceram. Int., 2015, 41, P. 8730-8734.

[12] Zagaynov I.V., Liberman, E.Yu., Naumkin A.V. $\mathrm{Gd}_{x} \mathrm{Zr}_{y} \mathrm{Ti}_{z} \mathrm{Ce}_{1-x-y-z} \mathrm{O}_{2}$ mesoporous catalysts for oxidation reactions. Surf. Sci., 2015, 642, P. L11-L15.

[13] Trovarelli A. Catalytic properties of ceria and $\mathrm{CeO}_{2}$-containing materials. Catal. Rev., 1996, 38, P. $439-520$.

[14] Alammar T., Chow Y.-K., Mudring A.-V. Energy efficient microwave synthesis of mesoporous $\mathrm{Ce}_{0.5} \mathrm{M}_{0.5} \mathrm{O}_{2}$ (Ti, $\mathrm{Zr}$, Hf) nanoparticles for low temperature $\mathrm{CO}$ oxidation in an ionic liquid - a comparative study. New J. Chem., 2015, 39, P. 1339-1347. 